\title{
Excess mortality in severe mental illness: 10-year population-based cohort study in rural Ethiopia
}

Abebaw Fekadu, Girmay Medhin, Derege Kebede, Atalay Alem, Anthony J. Cleare, Martin Prince, Charlotte Hanlon and Teshome Shibre

\section{Background}

Evidence on mortality in severe mental illness (SMI) comes primarily from clinical samples in high-income countries.

\author{
Aims \\ To describe mortality in people with SMI among a population \\ cohort from a low-income country.
}

\section{Method}

We followed-up 919 adults (from 68378 screened) with SMI over 10 years. Standardised mortality ratios (SMR) and years of life lost (YLL) as a result of premature mortality were calculated.

\section{Results}

In total 121 patients (13.2\%) died. The overall SMR was twice that of the general population; higher for men and people with schizophrenia. Patients died about three decades prematurely, mainly from infectious causes (49.6\%). Suicide, accidents and homicide were also common causes of death

\section{Conclusions}

Mortality is an important adverse outcome of SMI irrespective of setting. Addressing common natural and unnatural causes of mortality are urgent priorities. Premature death and mortality related to self-harm should be considered in the estimation of the global burden of disease for SMI.

\section{Declaration of interest}

None.
Premature mortality is a well-established adverse outcome of severe mental illness (SMI), most notably for schizophrenia, bipolar disorder and depressive disorder. ${ }^{1}$ Nonetheless, investigating mortality patterns remains important for: (a) for monitoring the profile of changing risk factors over time; ${ }^{2}$ (b) for evaluating the impact of sociocultural and geographic settings on mortality; (c) for reviewing the contribution of SMI to the global burden of disease; (d) for advocating for the inclusion of SMI in the global health agenda; and (e) to establish the mortality profile in population samples, which has not been demonstrated adequately to date. Moreover, the contribution of SMI to the global burden of disease has increased in the most recent analyses ${ }^{3,4}$ but is still likely to be underestimated substantially. For example, although mental disorders, particularly SMI, are the strongest predictors of mortality from self-harm, ${ }^{5}$ self-harm is calculated separately in the global burden of disease estimations. ${ }^{6}$ In addition, the indirect yet substantial contributions of mental disorders to mortality related to physical conditions are underrecognised in calculations of the global burden of disease. ${ }^{6,7}$ This underestimation has the potential to perpetuate the low prioritisation of mental disorders and the underinvestment in research and services related to SMI, particularly in low-income country settings, where policy-makers have to prioritise disorders with the highest burden and best outcome returns for their investment. Furthermore, our knowledge about mortality associated with SMI derives from clinical samples recruited in the context of service receipt or hospital admission, mostly from high-income countries, although over $80 \%$ of the world's population lives in low- and middleincome countries with limited access to treatment. The little knowledge we have about the mortality of people with SMI from low- and middle-income countries comes from anecdotal accounts $^{8}$ and the pioneering studies of the World Health Organization, which are now over three decades old. ${ }^{9-11}$ For example the International Pilot Study of Schizophrenia was initiated over 45 years ago, in $1966 .{ }^{11}$ Many changes have occurred in our understanding of mental disorders since: more refined methods of illness classification, case identification and monitoring have evolved; new methods for ascertainment of causes of mortality applicable in low-income settings have enabled researchers to define causes of death in more precise ways. Additionally, virtually no data exist on the mortality outcomes in bipolar disorder and severe depressive disorders in low-income country settings, which are also important contributors to premature mortality alongside schizophrenia. There is, therefore, a pressing need for up-to-date, methodologically rigorous, population-based studies from lowincome countries. The aim of this report is to present the mortality outcomes of people with SMI from the ButajiraEthiopia study on SMI, a recently completed large-scale, population-based cohort study.

\section{Method}

\section{The cohort}

The study cohort and the methods for follow-up have been described in detail previously. ${ }^{12-14}$ A summary description of the cohort is presented below with the focus on the conduct of the mortality assessment. The Butajira cohort on SMI was established between March 1998 and May 2001 in the Butajira district, located $132 \mathrm{~km}$ from Addis Ababa, the capital of Ethiopia. At the start of the study, the area was administratively divided into 46 subdistricts and all except one inaccessible subdistrict were included in the study. Demographically, the district contained predominantly rural sites with only four of the subdistricts, representing $10.9 \%$ of the population, being urban. This is similar to the urban-rural balance seen in the southern region of Ethiopia. ${ }^{15}$

The cohort was identified through a two-stage sampling design. In the first stage, potential participants with SMI (schizophrenia, bipolar disorder and severe depression) were identified through a supervised door-to-door survey and the key 
informant method. ${ }^{16}$ The door-to-door survey consisted of lay interview with the Composite International Diagnostic Interview (CIDI), version $2.1^{17}$ targeting adults aged $15-49$ years, estimated at the beginning of the study to be $83282 .{ }^{18}$ The CIDI was administered to 68378 individuals $(82.1 \%$ of the target population) and the CIDI case identification was augmented by trained key informants, community leaders and elders selected from each village. ${ }^{16}$ In the second stage, people with potential disorder were assessed using the Schedules for Clinical Assessment in Neuropsychiatry (SCAN), ${ }^{19}$ a structured instrument to confirm diagnosis. The SCAN was administered by trained clinicians and the ratings were validated against clinical diagnosis by psychiatrists, ${ }^{20}$ with excellent agreement between the SCAN diagnosis and clinical diagnosis. The first cohort identification lasted 3 years (1998-2001) and 844 participants were recruited. Using similar methodology, a leakage study identified 75 additional participants in the next 3 years from the same catchment area (Fig. 1). Thus, the total cohort consisted of 919 participants with SMI, composed mostly of men $(n=572,62.2 \%)$. This gender difference was primarily because the majority of individuals identified with schizophrenia were men $(n=296,82.7 \%)$. There was no gender difference in bipolar disorder and the difference in severe depression was in the expected direction; women were overrepresented $(n=132 ; 61.4 \%)$. Details of the baseline demographic characteristics are presented in Table 1.

\section{Monitoring of cohort and confirmation of survival status}

The cohort was monitored serially over a median of 11.3 years (interquartile range 10.7-11.9), ending in February 2012. Three

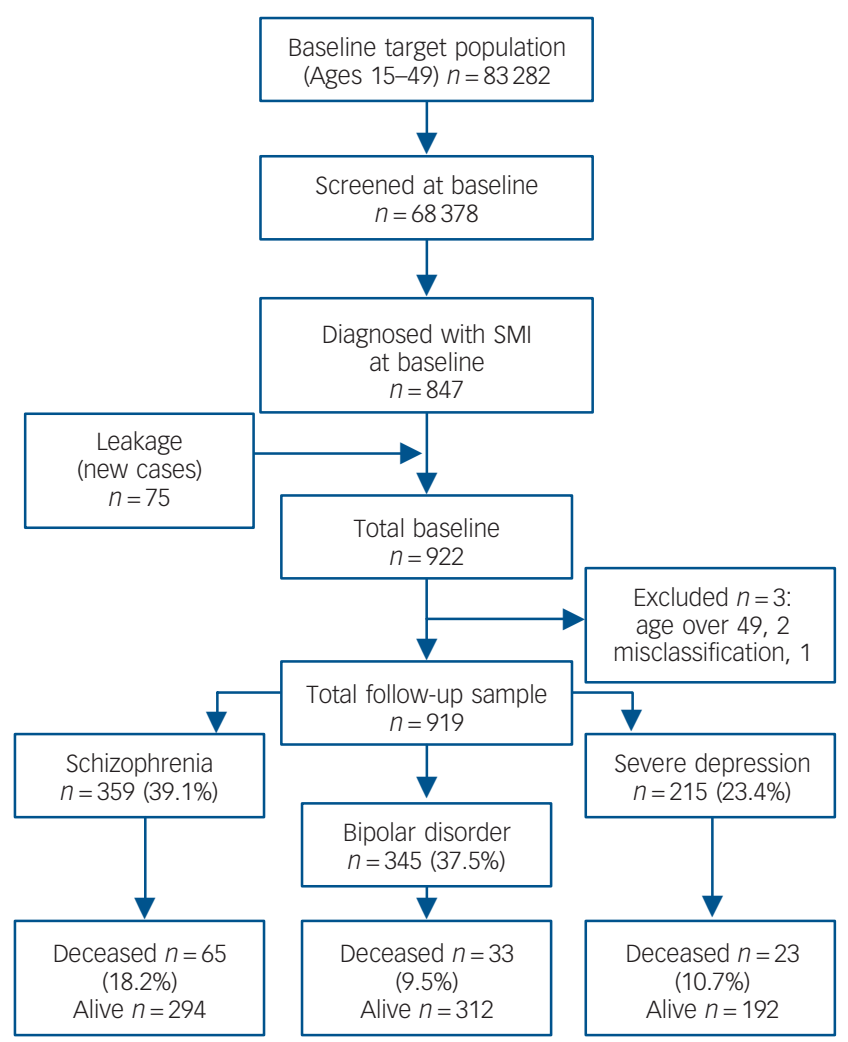

Fig. 1 Flow diagram of follow-up status and mortality over 10 years in the Butajira study, Ethiopia.

\begin{tabular}{|c|c|c|c|c|}
\hline \multirow[b]{2}{*}{ Characteristic } & \multirow[b]{2}{*}{ Total, $n(\%)$} & \multicolumn{3}{|c|}{ Disorder, $n$ (\%) } \\
\hline & & Schizophrenia & Bipolar disorder & Severe depression \\
\hline Gender & 919 & & & \\
\hline Male & $572(62.2)$ & $296(82.7)$ & $193(55.8)$ & $83(38.6)$ \\
\hline Female & 347 (37.8) & 62 (17.3) & $153(44.2)$ & $132(61.4)$ \\
\hline Age & 906 & & & \\
\hline $15-24$ & $252(27.8)$ & $83(23.0)$ & $121(35.2)$ & $48(22.7)$ \\
\hline $25-34$ & $362(40.0)$ & $154(42.7)$ & $135(39.2)$ & $73(34.6)$ \\
\hline $35-49$ & $292(32.2)$ & $124(34.3)$ & $88(25.6)$ & $90(42.7)$ \\
\hline Marital status & 904 & & & \\
\hline Single & 347 (38.4) & $192(54.7)$ & $111(32.4)$ & $44(20.9)$ \\
\hline Married & $449(49.7)$ & $97(27.6)$ & $208(60.6)$ & $144(68.2)$ \\
\hline Other & 108 (11.9) & $62(17.7)$ & $24(7.0)$ & 23 (10.9) \\
\hline Education & 904 & & & \\
\hline Non-literate & $573(63.4)$ & 189 (54.0) & $221(64.4)$ & $163(77.3)$ \\
\hline Literate & $331(36.6)$ & $161(46.0)$ & $122(35.6)$ & $48(22.7)$ \\
\hline Employment & 919 & & & \\
\hline Unemployed & $429(46.7)$ & $214(59.8)$ & $119(34.4)$ & $96(44.7)$ \\
\hline Employed & 490 (53.3) & $144(40.2)$ & $227(65.6)$ & 119 (55.3) \\
\hline Residence & 919 & & & \\
\hline Urban & $187(20.3)$ & $87(24.3)$ & 60 (17.3) & 40 (18.6) \\
\hline Rural & $732(79.7)$ & $271(75.7)$ & $286(82.7)$ & $175(81.4)$ \\
\hline Duration of illness & 841 & & & \\
\hline$\leqslant 2$ years & $197(23.4)$ & 77 (24.1) & $76(23.5)$ & $44(22.3)$ \\
\hline$>2 \leqslant 5$ years & $137(16.3)$ & $66(20.6)$ & $52(16.0)$ & 19 (9.6) \\
\hline$>5$ years & $507(60.3)$ & $177(55.3)$ & $196(60.5)$ & $134(68.0)$ \\
\hline Complete remissiona $^{a}$ & 919 & & & \\
\hline$\leqslant 50 \%$ of follow-up & $456(49.6)$ & $249(69.6)$ & $168(48.6)$ & $39(18.1)$ \\
\hline$>50 \%$ of follow-up & $463(50.4)$ & $109(30.4)$ & $178(51.4)$ & $176(81.9)$ \\
\hline Deceased & $121(13.2)$ & $65(18.2)$ & $33(9.5)$ & $23(10.7)$ \\
\hline Total & 919 & $358(39.0)$ & $346(37.6)$ & $215(23.4)$ \\
\hline
\end{tabular}


monitoring mechanisms were established. First, each subdistrict was allocated to trained field workers who were involved in the initial data collection. These field workers developed intimate knowledge of the patients and the family and provided a report on the status of patients about once per month. Second, patients had a monthly clinical follow-up at which time their clinical status, medication changes and any other relevant indicators were recorded. Third, all participants were assessed annually for diagnostic stability and symptom and functional status. Through this continuous monitoring the survival status of participants was ascertained prospectively for all entrants into the cohort.

Death was confirmed within 1 month of death by field workers who completed the verbal autopsy using the WHO verbal autopsy questionnaire that was previously adapted for use in the Butajira area. ${ }^{22,23}$ Verbal autopsy is described as the 'most promising' method of ascertaining causes of death in settings where most deaths occur at home and are not attended by a doctor as is the case in our study setting. ${ }^{24}$ The verbal autopsy method has also informed the latest global burden of disease data on causes of death from low- income settings. ${ }^{4,25}$ The verbal autopsy questionnaire is prepared for completion by lay interviewers based on information from close family members who have knowledge of the terminal illness. ${ }^{26-29}$ The verbal autopsy questionnaire starts by asking about basic sociodemographic and personal habits (smoking and alcohol use). This is followed by details about the circumstances leading to death (signs and symptoms of illness, duration of the identified signs and symptoms, and explores potential external causes).

The lay field workers of the Butajira study on SMI who administered the verbal autopsy questionnaire to close relatives of the deceased were trained in the administration of the questionnaire. Once the questionnaire was completed, decision on diagnosis of the cause of death was made by consensus of two physicians. The verbal autopsy data were supplemented by the Broad Rating Schedule (BRS). ${ }^{30}$ The BRS was originally developed to summarise the findings during follow-up of patients with a diagnosis of schizophrenia but the principles of the BRS are applicable to all disabling disorders. The symptomatic and functional status of the participants is rated for the last month. The rating is made based on all available information, including information from the participant, other informants and records. The BRS also assesses symptoms and disabilities using a modified version of the Global Assessment of Functioning scale (GAF). ${ }^{31}$ The score ranged from 1 (persistent inability to function in almost all areas) to 90 (good function in all areas). Generally a score of 60 and above is considered a reasonable level of functioning. The BRS contains sections on participants lost to follow-up and deceased. The causes of death were then grouped into broad ICD-10 disease classes $^{32}$ as presented in Table 3 .

\section{Analytic methods}

Data analysis was conducted with SPSS version 21 and Stata version 11 for Windows. Mortality was standardised using the latest (2007) census of the Southern Nations Nationalities Peoples Region of Ethiopia, ${ }^{15}$ which includes Butajira. In the absence of appropriate dates of birth, we followed the method proposed by Breslow \& Day ${ }^{33}$ to calculate person-years of follow-up, and relied on age at entry, date of entry and date of exit. We estimated the amount of time contributed by each individual to each 5-year age category and summed up all those contributions for all cohort members and obtained the total number of person-years of observation in that category. Each participant was assumed to contribute 0.5 years to the age category of the participant at commencement in the study, but the precise follow-up duration was calculated for the exit year. A full 1 year was given to each intervening year. For participants exiting the study within a year of entry into the cohort the exact length of contributed time was calculated. We estimated the potential years of life lost (YLL) using the 2009 national data on life expectancy. ${ }^{34}$ As was the case in the global burden of disease estimation, ${ }^{4,35}$ YLL were computed by multiplying the number of deaths at each age $(x$ years) by the standard life expectancy of the reference population (the Ethiopia population) at age x. Put slightly differently, YLL was computed by estimating the difference between the actual age at death of an individual in the cohort who died from any cause, and the expected age at death. This may be represented with the following formula: ${ }^{36} \mathrm{YLL}=\Sigma d i(E-i)$, where $i=$ actual age at death; $d=$ number of deaths at age $i$; and $\mathrm{E}=$ Expected age at death estimated according to the 2009 life tables for Ethiopia, based on age and gender. The sum of the YLL was then divided by the number of deceased individuals to derive the mean YLL. Standardised mortality ratios were calculated as the ratio of the number of observed deaths in the sample with SMI to the number expected if the sample with SMI had the same mortality rate as the population within Southern region. Factors associated with premature mortality were computed using the Cox proportional hazards model. We also estimated the life expectancy at birth of the cohort based on the life expectancy of the population of the Southern region using Chiang's method of abridged life tables in 5-year groups. ${ }^{37-39}$ This method has been recommended for its application to relatively small populations. ${ }^{38}$ Since those under 15 years of age would be unlikely to receive a diagnosis of SMI, the mortality rates of the Southern Region for the under-15-years age groups was applied in substitution. ${ }^{40}$ Additionally, we substituted the mortality rates of the Southern region for mortality above 60 because only a small number of participants had been above $60(n=6)$ and using the SMI cohort would lead to unstable estimation. Life expectancy was estimated for the whole cohort and by gender as well as by the three disorders. The differences in life expectancy at birth between those with SMI and that of the Southern region were calculated.

\section{Ethical considerations}

The study was initially approved by the ethics committee of the Department of Community Health and then by the Institutional Review Board of the Faculty of Medicine and the College of Health Sciences of Addis Ababa University. Treatment was made available free of charge for all patients needing treatment.

\section{Results}

In total 121 participants (13.2\% of the initial cohort) died during the follow-up period. Details of the demographic characteristics are presented in Table 1 . Nearly twice as many patients with schizophrenia died $(n=65,18.2 \%)$ compared with those with bipolar disorder $\left(n=33,9.5 \%, \chi^{2}(1)=10.9, P=0.001\right)$ or severe depression $\left(n=23,10.7 \% ; \chi^{2}(1)=5.7, P=0.016\right)$. When all diagnostic categories were considered together, more deaths occurred among men $(n=88,15.4 \%)$ than women $(n=33$, $9.5 \%, \chi^{2}(1)=6.5, P=0.011$ ). However, the difference was not statistically significant when comparison was stratified by diagnostic groups even though comparatively more men died in all categories: $19.3 \%$ v. $12.9 \%$ for schizophrenia, $10.9 \%$ v. $7.8 \%$ for bipolar disorder and $12.0 \%$ v. $9.8 \%$ for severe depression.

Overall, mortality was twice that of the standard population (SMR $=213.9,95 \%$ CI 177-256) (Table 2). The SMR was highest for schizophrenia (302.7, 95\% CI 234-386), which was significantly higher than that of bipolar disorder $(\mathrm{SMR}=150.1$, 
Table 2 Standardised mortality ratio (SMR) for severe mental illness computed using the population of the Southern region as the reference

\begin{tabular}{|lc|}
\hline Categories & SMR \\
\hline Overall $^{\mathrm{a}}$ & $213.9(177.0-256.0)$ \\
\hline $\begin{array}{l}\text { Gender }^{\mathrm{b}} \\
\text { Male }\end{array}$ & $225.6(181.0-278.0)$ \\
Female & $170.3(117.0-239.0)$ \\
\hline $\begin{array}{l}\text { Diagnosis } \\
\text { Schizophrenia }\end{array}$ & \\
Bipolar disorder & $302.7(234.0-386.0)$ \\
Severe depression & $150.1(103.0-211.0)$ \\
$\begin{array}{l}\text { a. Age and gender standardised. } \\
\text { b. Age standardised. }\end{array}$ \\
\hline
\end{tabular}

95\% CI 103- 211) although not that of severe depression $(\mathrm{SMR}=169.9,95 \%$ CI 108- 255).

The commonest cause of death, based on categories of the ICD-10, ${ }^{32}$ was related to infectious conditions $(49.6 \%, n=60)$ prevalent in the study area (Table 3 ). Unnatural causes accounted for a quarter of all causes of death $(24.8 \%, n=30)$, most arising from suicide $(n=19,15.7 \%)$; the rest from other unnatural causes such as road traffic accidents and homicide $(n=11)$. Proportionately, those with bipolar disorder had the highest mortality from suicide $(24.2 \%, n=8 / 33)$ although the difference was not statistically significant compared with both those with schizophrenia $(13.8 \%, n=9 / 65)$ and severe depression $(8.6 \%$, $n=2 / 23)$. Deaths from the various causes peaked in the first 5 years of follow-up and were more or less constant afterwards (Fig. 2).

On average the YLL per person for all patients with SMI was 28.4 years. The YLL was slightly higher among women (30.0 years) compared with men (26.9 years). The YLL was also slightly higher for those with severe depression (29.4 years) compared with that for those with schizophrenia (27.7 years) and bipolar disorder (29.0 years). However, because of the larger number of patients who died, schizophrenia made the largest contribution to the overall YLL (52.4\%), followed by bipolar disorder (27.9\%) and severe depression (19.7\%). Whereas deaths related to injuries accounted for $22.4 \%$ of YLL, suicide alone contributed to $8.7 \%$ of all YLL. Overall, those with SMI had a life expectancy gap of about 6 years and it was nearly 10 years for those with schizophrenia and depression (Table 4). The life expectancy gap for men and women was 5 and 6 years, respectively.

The two factors associated independently with mortality were male gender, and shorter time in remission (Table 5). Thus, those who were in remission for less than $50 \%$ of the follow-up period had double the risk of dying (Hazard Ratio $(\mathrm{HR})=2.02,95 \% \mathrm{CI}$ $1.31-3.12, \quad P=0.002)$. Men also had increased mortality $(\mathrm{HR}=1.67,95 \% \mathrm{CI} 1.04-2.66, P=0.032)$. Older age at enrolment into the study did not significantly increase the risk although there may be a trend $(\mathrm{HR}=1.85,95 \%$ CI $0.98-3.12, P=0.060)$. For all

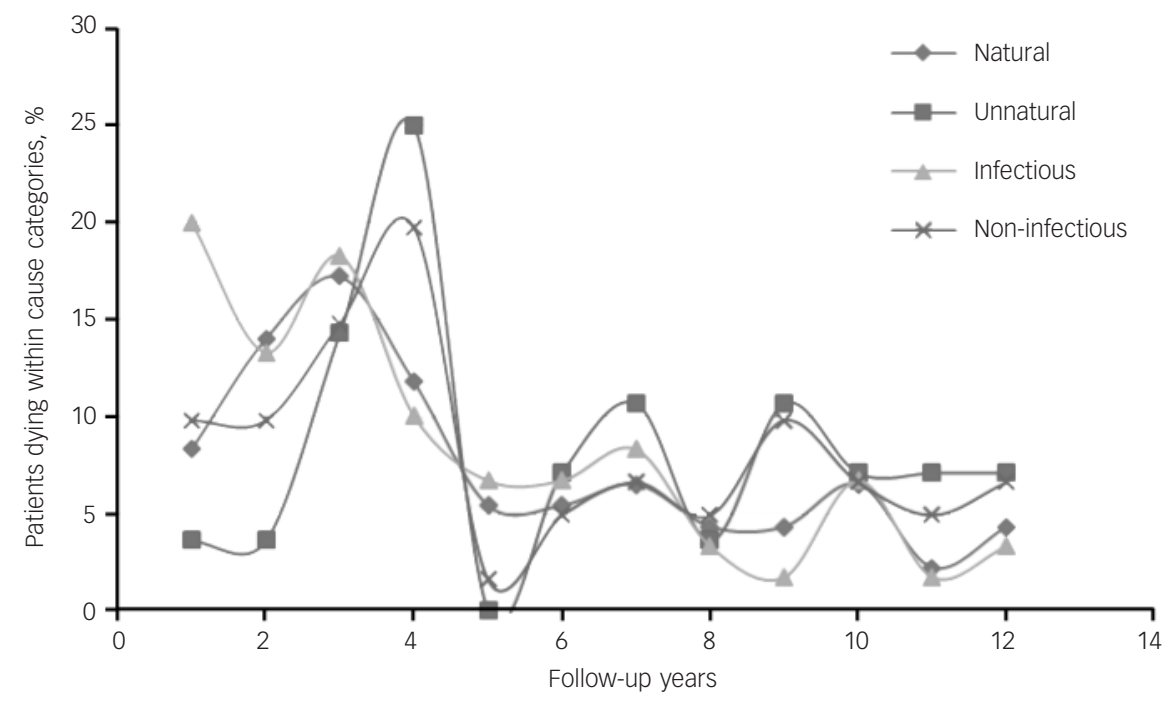

Fig. 2 Percentage of patients dying by follow-up years in broad cause categories (natural $v$. unnatural and infectious $v$. non-infectious) indicating pattern of death over time.

\begin{tabular}{|c|c|c|}
\hline Mortality cause category & ICD-10 class & $n(\%)$ \\
\hline Certain infectious and parasitic diseases & । & $60(49.6)$ \\
\hline Neoplasms & II & $3(2.5)$ \\
\hline Endocrine, nutritional and metabolic diseases & IV & $4(3.3)$ \\
\hline Diseases of the nervous system & $\mathrm{Vl}$ & $1(0.8)$ \\
\hline Diseases of the respiratory system & $x$ & $6(5.0)$ \\
\hline Diseases of the digestive system & $\mathrm{XI}$ & $7(5.8)$ \\
\hline Diseases of the genitourinary system & XIV & $2(1.6)$ \\
\hline Symptoms, signs and abnormal clinical and laboratory findings, not elsewhere classified & $\mathrm{XVII}$ & $8(6.6)$ \\
\hline Injury, poisoning and certain other consequences of external causes (suicide) & $\mathrm{XIX}$ & $19(15.7)$ \\
\hline External causes of morbidity and mortality (accidents) & $X X$ & $11(9.1)$ \\
\hline Total & - & $121(100)$ \\
\hline
\end{tabular}


Table 4 Life expectancy at birth (with $95 \% \mathrm{Cl}$ ) of people with severe mental illness (SMI) computed based on the general population of the region

Expectancy years, mean $(95 \% \mathrm{Cl})$

$\begin{array}{ll}\text { Southern region } & \\ \text { Total } & 55.66(50.57-60.75) \\ \text { Men } & 52.31(46.99-57.63) \\ \text { Women } & 59.64(54.81-64.47) \\ \text { Butajira } & \\ \text { All SMI } & 49.25(44.55-53.95) \\ \text { Men with SMI } & 47.18(42.31-52.05) \\ \text { Women with SMI } & 53.99(48.94-59.04) \\ \text { Schizophrenia } & 46.27(41.92-50.62) \\ \text { Bipolar disorder } & 54.12(49.14-59.10) \\ \text { Severe depression } & 46.34(39.94-52.74)\end{array}$

disorder subtypes, longer periods in a symptomatic state were associated with shorter survival time (Table 6). For each of the diagnostic groups, spending a higher percentage of follow-up time in episode was associated with an increased risk of premature mortality. For those with depressive disorder (but not the other disorders), subthreshold symptoms were also associated with risk of premature mortality.

In the month prior to death, most of the deceased were symptomatic $(70.2 \%, n=85 / 121)$ and functionally impaired $(75.2 \%$, $n=91 / 121$ ) because of their mental illness (Table 7). Impairment was consistently high across diagnostic groups: schizophrenia (78.5\%), bipolar disorder (75.8\%) and severe depression (65.3\%). Similarly, high percentages of the deceased were symptomatic across the diagnostic groups: schizophrenia $(n=44$, $68.8 \%)$; bipolar disorder $(n=26,78.8 \%)$ and severe depression

\begin{tabular}{|c|c|c|c|c|}
\hline Variable & $n$ & Unadjusted HR (95\% Cl) & Fully adjusted HR (95\% Cl) & $P$ \\
\hline \multicolumn{5}{|l|}{ Gender } \\
\hline Female & 347 & Ref & Ref & \\
\hline Male & 572 & $1.66(1.12-2.48)$ & $1.67(1.04-2.66)$ & 0.032 \\
\hline \multicolumn{5}{|l|}{ Marital status } \\
\hline Married & 449 & Ref & Ref & \\
\hline Single & 347 & $1.37(0.93-2.03)$ & $1.29(0.78-2.15)$ & 0.315 \\
\hline Other & 109 & $1.61(0.95-2.73)$ & $1.24(0.70-2.20)$ & 0.455 \\
\hline \multicolumn{5}{|l|}{ Age, years } \\
\hline $15-24$ & 253 & Ref & Ref & \\
\hline $25-34$ & 370 & $1.37(0.83-2.26)$ & $1.14(0.64-3.52)$ & 0.647 \\
\hline $35-49$ & 295 & $1.97(1.21-3.22)$ & $1.85(0.98-3.12)$ & 0.060 \\
\hline \multicolumn{5}{|l|}{ Residence } \\
\hline Rural & 732 & Ref & Ref & \\
\hline Urban & 187 & $1.20(0.78-1.83)$ & $1.15(0.73-1.82)$ & 0.542 \\
\hline \multicolumn{5}{|l|}{ Diagnosis } \\
\hline Severe depression & 215 & Ref & Ref & \\
\hline Bipolar disorder & 346 & $0.87(0.51-1.49)$ & $1.04(0.58-1.84)$ & 0.905 \\
\hline Schizophrenia & 358 & $1.77(1.10-2.84)$ & $0.81(0.44-1.49)$ & 0.491 \\
\hline \multicolumn{5}{|l|}{ Illness duration } \\
\hline$\leqslant 2$ years & 197 & Ref & Ref & \\
\hline$>2 \leqslant 5$ years & 137 & $0.84(0.42-1.66)$ & $0.71(0.35-1.43)$ & 0.339 \\
\hline$>5$ years & 507 & $1.37(0.85-2.20)$ & $1.24(0.74-2.08)$ & 0.422 \\
\hline \multicolumn{5}{|l|}{ Illness severity ${ }^{b}$} \\
\hline $\mathrm{GAF}>60$ & 672 & Ref & Ref & \\
\hline $\mathrm{GAF} \leqslant 60$ & 247 & $2.06(1.26-3.35)$ & $1.55(0.68-2.04)$ & 0.557 \\
\hline \multicolumn{5}{|l|}{ Illness course ${ }^{c}$} \\
\hline Remission $>50 \%$ & 463 & Ref & Ref & \\
\hline Remission $\leqslant 50 \%$ & 456 & $2.38(1.62-3.49)$ & $2.02(1.31-3.12)$ & 0.002 \\
\hline
\end{tabular}

\begin{tabular}{|c|c|c|c|c|c|c|}
\hline \multirow[b]{3}{*}{ Nature of symptoms } & \multicolumn{6}{|c|}{ Diagnostic class } \\
\hline & \multicolumn{2}{|c|}{ Schizophrenia } & \multicolumn{2}{|c|}{ Severe depression } & \multicolumn{2}{|c|}{ Bipolar disorder } \\
\hline & $\mathrm{HR}(95 \% \mathrm{Cl})$ & $P$ & $\mathrm{HR}(95 \% \mathrm{Cl})$ & $P$ & $\mathrm{HR}(95 \% \mathrm{Cl})$ & $P$ \\
\hline Percentage in episode & $1.02(1.01-1.03)$ & $<0.001$ & - & & - & \\
\hline Percentage in episode and subthreshold & $1.02(1.01-1.03)$ & $<0.001$ & - & & - & \\
\hline Percentage in depressive episode & & & $1.06(1.03-1.09)$ & $<0.001$ & $1.03(1.00-1.07)$ & 0.098 \\
\hline Percentage in subthreshold depression & & & $1.02(1.00-1.04)$ & 0.032 & $1.02(1.00-1.04)$ & 0.149 \\
\hline Percentage in episode and subthreshold depression & & & $1.03(1.02-1.05)$ & $<0.001$ & $1.02(1.00-1.03)$ & 0.075 \\
\hline Percentage in manic episode & - & & & & $1.05(1.02-1.07)$ & $<0.001$ \\
\hline Percentage in episode and subthreshold mania & - & & & & $1.02(1.01-1.04)$ & 0.011 \\
\hline
\end{tabular}


Table 7 Clinical and functional status of participants who died in the month preceding their death and role of the severe mental illness (SMI) in the death as determined by a physician

\begin{tabular}{|c|c|c|c|c|}
\hline \multirow[b]{2}{*}{ Status and impact } & \multicolumn{3}{|c|}{ Diagnosis, $n$ (\%) } & \multirow[b]{2}{*}{ Total, $n(\%)$} \\
\hline & Schizophrenia & Bipolar disorder & Severe depression & \\
\hline \multicolumn{5}{|l|}{ Clinical status } \\
\hline Well & $20(31.3)$ & $6(18.8)$ & $8(34.8)$ & $34(28.6)$ \\
\hline Partial episode & $19(29.7)$ & $12(37.5)$ & $6(26.1)$ & $37(31.1)$ \\
\hline Full episode & $25(39.1)$ & $14(43.8)$ & $9(39.1)$ & $48(40.3)$ \\
\hline \multicolumn{5}{|l|}{ Functional status ${ }^{a}$} \\
\hline Very good & $2(3.2)$ & $2(6.1)$ & $2(8.7)$ & $6(5.0)$ \\
\hline Good & $5(7.9)$ & $2(6.1)$ & $1(4.3)$ & $8(6.7)$ \\
\hline Fair & $5(7.9)$ & $4(12.1)$ & $5(21.7)$ & $14(11.8)$ \\
\hline Poor & $13(20.6)$ & $10(30.3)$ & $4(17.4)$ & $27(22.7)$ \\
\hline Very poor & $38(60.3)$ & $15(45.5)$ & $11(47.8)$ & $64(52.8)$ \\
\hline \multicolumn{5}{|l|}{ SMI as a cause of death } \\
\hline Caused & $19(30.2)$ & $6(18.8)$ & $9(39.1)$ & $34(28.8)$ \\
\hline Related but not caused & $17(27.0)$ & $8(25.0)$ & $4(17.4)$ & $29(24.6)$ \\
\hline Independent & $26(41.3)$ & $16(50.0)$ & $10(43.5)$ & $53(44.1)$ \\
\hline Unknown & $1(1.6)$ & $2(6.3)$ & 0 & $3(2.5)$ \\
\hline
\end{tabular}

$(n=15,64.2 \%)$. Moreover, mental disorders were considered to be relevant to the death in over half of the deaths either because they were presumed to have led directly to death $(n=34,28.8 \%)$ or were linked to the death $(n=29,24.6 \%)$.

\section{Discussion}

To our knowledge this is the largest single-site study describing mortality in SMI from a low-income country setting. It is also one of the very few studies in the world describing mortality experience of community-ascertained cases with minimum treatment exposure. The study has several novel features that contribute to addressing the gap in our knowledge about mortality associated with SMI. First, the study employed rigorous community-based case identification and diagnostic methods, screening a population of over 68000 people, and has monitored the individuals identified continuously over an average of 10 years of follow-up. Second, the cohort had very low treatment exposure at recruitment. Third, the report provides data on mortality associated with bipolar disorder and severe depression, where we have virtually no data from low-income countries. Finally, the causes of mortality were established close to the time of death and used validated methodologies. Moreover, by using prospective clinical and functional measures, our study also contributes to the evidence on the potential role of psychopathology in causing premature mortality.

\section{Main findings}

The study confirms that people with SMI, irrespective of setting, are at increased risk of mortality. Specifically, in this particular setting, the risk of mortality among those with SMI was double that of the general population, which is consistent with previous reports of mortality and SMI in high-income countries, ${ }^{41-49}$ However, the mortality figures were lower than what we had anticipated. This may be partly because of the increased mortality in the general population related to the high burden of preventable causes other than injuries. ${ }^{22,23}$ The SMR is also lower than the figure we previously reported based on a 5-year follow-up study of schizophrenia. ${ }^{50}$ This is likely to be because of higher mortality in the early parts of the follow-up as demonstrated in Fig. 2. Moreover, increased risk of early mortality has been demonstrated in service contact samples of both schizophrenia ${ }^{51,52}$ and mood disorders, ${ }^{45}$ particularly for unnatural causes. ${ }^{53}$ Thus, the previous report may have suffered from the short-term nature of the study given the higher burden of mortality in the early phases of the follow-up period. This is of interest from both a research and service perspective. In terms of research, longer term studies of mortality are more likely to provide more stable and more accurate estimation and should be encouraged. From a service perspective, given the mixed nature of our cohort, which was composed of both individuals with chronic and recent-onset disorders, the finding underscores the need for vigilance in the early periods of service provision irrespective of the duration of illness at the time of first-service contact. However, we cannot rule out the possibility that the reduction in mortality might have been as a result of better care provision related to recent restructurings in the healthcare system, for example, expansion of primary healthcare, although this would be expected to have a greater impact on the population without SMI. A distinct methodology would be required to detect the impact of health system changes on mortality. Based on the current findings, however, we recommend that provision of enhanced care in the early phases of the illness may be essential to improving the mortality outcomes of people with SMI.

\section{Deaths from infectious diseases}

Most patients in the study died from infectious causes prevalent within Butajira. ${ }^{23}$ This is partly a reflection of the limited care available for the population. Therefore, improving the general health of the public is likely to have an impact on the survival of people with SMI. Patients with SMI may also be at a particular disadvantage because they may not complain when they have symptoms, and family support may have been already overstretched when patients develop infections. Further exploration of the mechanisms underlying death from infectious conditions is warranted.

\section{Deaths from unnatural causes}

A large proportion of individuals have also died from unnatural causes, primarily suicide. Studies of suicide in Ethiopia have reported the rate to be between 6 and 8 per 100000 per year. $^{54,55}$ The rate among patients with SMI in the Butajira cohort was 
about 200 per 100000 per year, a substantially higher rate. The overall mortality rate from all unnatural causes was also high, accounting for $24.8 \%$ of all causes $(n=30 / 121)$ compared with the rate in the Butajira area which has been estimated at $1.7 \% .^{23}$ In a study from Addis Ababa, the capital of Ethiopia, unnatural causes of death other than suicide accounted for a higher rate $(11.2 \%)^{55}$ although still around $50 \%$ lower than that of the Butajira sample with SMI.

\section{Contribution of psychopathology to mortality}

Given the high rate of deaths from unnatural causes and the high level of psychopathology in the deceased group, it is likely that psychopathology contributed to the death of many patients. This is supported by the finding that SMI was likely to have contributed directly to the deaths of at least a third of all deaths and contribute substantially to the other deaths. Additional evidence for the potential contribution of psychopathology to mortality comes from the survival analyses in which better survival was predicted by longer periods in remission, while longer duration in a symptomatic state was associated with increased mortality in all disorder categories. Two recommendations follow from these findings. First, it is reasonable to suggest that improving mental healthcare provision may improve mortality outcomes. Second, the contribution of psychopathology to mortality has to be accounted for in the estimation of the global disease burden although this may call for a new technology.

\section{Life expectancy}

People with SMI lost about three decades of their life to premature death in this rural Ethiopian setting. Extrapolating this nationally, people with SMI lose a substantial amount of potential life years annually. Despite overlap in confidence intervals with the Southern region, the findings regarding the life expectancy gaps are important. A life expectancy at birth for people with schizophrenia and depression (46 years) is very low. Given the low life expectancy of the population in general, the life expectancy figures are worth paying attention to and have to be taken as evidence of the substantial neglect of people with SMI in such settings. Moreover, this study will serve as a baseline for future studies of the life expectancy gap in people with SMI in Ethiopia, which is likely to grow with improvement in the life expectancy of the general population.

\section{Limitations}

There are a few limitations worth mentioning. First, because of the lack of data on national cause-specific mortality, we were unable to present cause-specific mortality ratios for people with SMI. Second, cause of mortality confirmed by a physician would have been the best approach to determine causes of mortality; however, short of a physician determination, we have used the next best approach, the verbal autopsy method. The historical nature of the verbal autopsy assessment may have led to random misclassification of cause of mortality. Finally, information related to self-harm is not always volunteered. Therefore, the figure for suicide may be an underestimate.

\section{Implications}

This relatively large-scale cohort study from rural Ethiopia confirms the increased risk of mortality associated with SMI irrespective of setting. The study re-establishes mortality as a very important outcome for people with SMI in low-income settings despite the high burden of premature mortality from diverse preventable causes. The study adds new data not only on mortality in people with SMI in low-income countries, but also to the worldwide database on mortality among those with SMI identified and living in the community. The study highlights the need to improve the mental healthcare as well as the physical healthcare of people with SMI. The study also makes a case for the inclusion of mortality directly attributable to mental disorders in the estimation of the global disease burden. This is important to increase the visibility of mental health in the public health agenda, reflecting its rightful place.

Abebaw Fekadu, MD, MSC, MRCPsych, PhD, Department of Psychiatry, College of Health Sciences, Addis Ababa University, Addis Ababa, Ethiopia and King's College London, Institute of Psychiatry, Psychology and Neuroscience, Department of Psychological Medicine, Centre for Affective Disorders, London, UK; Girmay Medhin MSc, PhD, Institute of Pathobiology, Addis Ababa University, Addis Ababa, Ethiopia; Derege Kebede, MD, DSC, WHO Regional Office for Africa, Brazzaville, Republic of Congo; Atalay Alem, MD, PhD, Department of Psychiatry, College of Health Sciences, Addis Ababa University, Addis Ababa, Ethiopia; Anthony J. Cleare, BSC, Sciences, Addis Ababa University, Addis Ababa, Ethiopia; Anthony J. Cleare, BSC,
MBBS, MRCPsych, PhD, King's College London, Institute of Psychiatry, Psychology and Neuroscience, Department of Psychological Medicine, Centre for Affective Disorders, London, UK; Martin Prince, MD, MSC, FRCPsych, King's College London, Institute of Psychiatry, Psychology and Neuroscience, Health Services and Population Research Department; charlotte Hanlon, BMBS, MSC, MRCPSych, PhD, Teshome Shibre, MD, PhD, Department of Psychiatry, College of Health Sciences, Addis Ababa University, Addis Ababa, Ethiopia.

Correspondence: Abebaw Fekadu, Addis Ababa University, College of Health Sciences, School of Medicine, Department of Psychiatry, PO Box 9086, Addis Ababa, Ethopia. Email: abe.wassie@kcl.ac.uk

First received 30 Mar 2014, final revision 15 Jul 2014, accepted 19 Sep 2014

\section{References}

1 Saha S, Chant D, McGrath J. A systematic review of mortality in schizophrenia: is the differential mortality gap worsening over time? Arch Gen Psychiatry 2007; 64: 1123-31.

2 Tsuang MT, Simpson JC. Mortality studies in psychiatry: should they stop or proceed? Arch Gen Psychiatry 1985; 42: 98-103.

3 Murray CJ, Lopez AD. Global mortality, disability, and the contribution of risk factors: Global Burden of Disease Study. Lancet 1997; 349: 1436-42.

4 Murray CJ, Vos T, Lozano R, Naghavi M, Flaxman AD, Michaud C, et al. Disability-adjusted life years (DALYs) for 291 diseases and injuries in 21 regions, 1990-2010: a systematic analysis for the Global Burden of Disease Study 2010. Lancet 2012; 380: 2197-223.

5 Cavanagha JTO, Carsib AJ, Sharpe M, Lawrie SM. Psychological autopsy studies of suicide: a systematic review. Psychol Med 2003; 33: 395-405.

6 Prince M, Patel V, Saxena S, Maj M, Maselko J, Phillips MR, et al. No health without mental health. Lancet 2007; 370: 859-77.

7 Blazer DG, Hybels CF, Pieper CF. The association of depression and mortality in elderly persons: a case for multiple, independent pathways. J Gerontol A Biol Sci Med Sci 2001; 56: 505-9.

8 Thornicroft G. Premature death among people with mental illness: at best a failure to act on evidence; at worst a form of lethal discrimination. BMJ 2013; 346: f2969.

9 Jablensky A, Sartorius N, Ernberg G, Anker M, Korten A, Cooper JE, et al. Schizophrenia: manifestations, incidence and course in different cultures. A World Health Organization ten-country study. Psychol Med Monogr Suppl 1992; 20: 1-97.

10 Sartorius N, Jablensky A, Korten A, Ernberg G, Anker M, Cooper JE, et al. Early manifestations and first-contact incidence of schizophrenia in different cultures. A preliminary report on the initial evaluation phase of the WHO Collaborative Study on determinants of outcome of severe mental disorders. Psychol Med 1986; 16: 909-28.

11 Sartorius N, Shapiro R, Jablensky A. The international pilot study of schizophrenia. Schizophr Bull 1974; 1: 21-34.

12 Alem A, Kebede D, Fekadu A, Shibre T, Fekadu D, Beyero T, et al. Clinical course and outcome of schizophrenia in a predominantly treatment-naive cohort in rural Ethiopia. Schizophr Bull 2009; 35: 646-54.

13 Fekadu A, Kebede D, Alem A, Fekadu D, Mogga S, Negash A, et al. Clinical outcome in bipolar disorder in a community-based follow-up study in Butajira, Ethiopia. Acta Psychiatr Scand 2006; 114: 426-34. 
14 Kebede D, Alem A, Shibre T, Negash A, Fekadu A, Fekadu D, et al. Onset and clinical course of schizophrenia in Butajira-Ethiopia-a community-based study. Soc Psychiatry Psychiatr Epidemiol 2003; 38: 625-31.

15 Federal Democratic Republic of Ethiopia Population Census Commission. Summary and Statistical Report of the 2007 Population And Housing Census: Population Size by Age and Sex. Federal Democratic Republic of Ethiopia Population Census Commission, 2008.

16 Shibre T, Kebede D, Alem A, Negash A, Kibreab S, Fekadu A, et al. An evaluation of two screening methods to identify cases with schizophrenia and affective disorders in a community survey in rural Ethiopia. Int $J$ Soc Psychiatry 2002; 48: 200-8.

17 World Health Organization. Composite International Diagnostic Interview (CIDI), Core version, 2.1. WHO, 1997.

18 Office of Population and Housing Census Commission (OPHCC). The 1994 Population and Housing Census of Ethiopia. Results for Southern Nations, Nationalities and Peoples' Region. Volume 1: Part V. Abridged Statistical Report. Central Statistical Authority, 1996.

19 World Health Organization. Schedules for Clinical Assessment in Neuropsychiatry, version 2.1 (SCAN 2.1). WHO, 1997.

20 Alem A, Kebede D, Shibre T, Negash A, Deyassa N. Comparison of computer assisted scan diagnoses and clinical diagnoses of major mental disorders in Butajira, rural Ethiopia. Ethiop Med J 2004; 42: 137-43.

21 Keller MB, Lavori PW, Friedman B, Nielsen E, Endicott J, McDonald-Scott P, et al. The Longitudinal Interval Follow-up Evaluation. A comprehensive method for assessing outcome in prospective longitudinal studies. Arch Gen Psychiatry 1987; 44: 540-8.

22 Fantahun $\mathrm{M}$, Berhane $\mathrm{Y}$, Hogberg $\mathrm{U}$, Wall S, Byass $\mathrm{P}$. Young adult and middle age mortality in Butajira demographic surveillance site, Ethiopia: lifestyle gender and household economy. BMC Public Health 2008; 8: 268.

23 Lulu K, Berhane Y. The use of simplified verbal autopsy in identifying causes of adult death in a predominantly rural population in Ethiopia. BMC Public Health 2005; 5: 58 .

24 Anker M. The effect of misclassification error on reported cause-specific mortality fraction from verbal autopsy. Int J Epidemiology 1997; 26: 1090-6.

25 Wang $\mathrm{H}$, Dwyer-Lindgren L, Lofgren KT, Rajaratnam JK, Marcus JR, Levin-Rector A, et al. Age-specific and sex-specific mortality in 187 countries, 1970-2010: a systematic analysis for the Global Burden of Disease Study 2010. Lancet 2012; 380: 2071-94.

26 Reeves BC, Quigley M. A review of data-derived methods for assigning causes of death from verbal autopsy data. Int J Epidemiol 1997; 26: 1080-9.

27 Ronsmans C, Vanneste AM, Chakraborty J, Van Ginneken J. A comparison of three verbal autopsy methods to ascertain levels and causes of maternal deaths in Matlab, Bangladesh. Int J Epidemiol Infect 1998; 27: 660-6.

28 Chandramohan D, Maude GH, Rodrigues LC, Hayes RJ. Verbal autopsies for adult deaths: issues in their development and validation. Int J Epidemiol 1994; 23: 213-22.

29 Quigley MA, Chandramohan D, Setel P, Binka F, Rodrigues LC. Validity of data-derived algorithms for ascertaining causes of adult death in two African sites using verbal autopsy. Trop Med Int Health 2000; 5: 33-9.

30 World Health Organization. Catalogue of WHO Psychiatric Assessment Instruments. Division of Mental Health, World Health Organization, 1995.

31 American Psychiatric Association. Diagnostic and Statistical Manual of Mental Disorders (3rd edn, revised). American Psychiatric Association, 1987.

32 World Health Organization. International Statistical Classification of Diseases and Related Health Problems 10th Revision. WHO, 2010

33 Breslow NE, Day NE. The Design and Analysis of Cohort Studies: 49-79. International Agency for Research on Cancer, 1987

34 World Health Organization. World Health Statistics 2012: Life Tables for WHO Member States. WHO, 2012.
35 Lozano R, Naghavi M, Foreman K, Lim S, Shibuya K, Aboyans V, et al. Global and regional mortality from 235 causes of death for 20 age groups in 1990 and 2010: a systematic analysis for the Global Burden of Disease Study 2010 Lancet 2012; 380: 2095-128.

36 Pham T-M, Fujino $\mathrm{Y}$, Ide R, Tokui N, Kubo T, Mizoue T, et al. Years of life lost due to cancer in a cohort study in Japan. Eur J Public Health 2009; 19: 189-92.

37 Chang $C K$, Hayes RD, Broadbent M, Fernandes AC, Lee W, Hotopf M, et al. All-cause mortality among people with serious mental illness (SMI), substance use disorders, and depressive disorders in southeast London: a cohort study. BMC Psychiatry 2010; 10: 77.

38 Chiang CL. The Life Table and its Applications. Robert E. Krieger, 1984

39 Lawrence D, Hancock KJ, Kiseley S. The gap in life expectancy from preventable physical illness in psychiatric patients in Western Australia: retrospective analysis of population based registers. BMJ 2013; 346: f2539.

40 Office for National Statistics. Mortality Statistics, Deaths Registered in 2008. ONS, 2009

41 Nordentoft M, Wahlbeck K, Hallgren J, Westman J, Osby U, Alinaghizadeh $\mathrm{H}_{\text {, }}$ et al. Excess mortality, causes of death and life expectancy in 270,770 patients with recent onset of mental disorders in Denmark, Finland and Sweden. PLOS One 2013; 8: e55176.

42 Gale CR, Batty GD, Osborn DP, Tynelius P, Whitley E, Rasmussen F. Association of mental disorders in early adulthood and later psychiatric hospital admissions and mortality in a cohort study of more than 1 million men. Arch Gen Psychiatry 2012; 69: 823-31.

43 Bushe C, Taylor M, Haukka J. Mortality in schizophrenia. J Psychopharmacol 2012; 26: 1285

44 Hoang U, Stewart R, Goldacre MJ. Mortality after hospital discharge for people with schizophrenia or bipolar disorder: retrospective study of linked English hospital episode statistics, 1999-2006. BMJ 2011; 343: d5422.

45 Angst $\mathrm{F}$, Stassen $\mathrm{HH}$, Clayton PJ, Angst J. Mortality of patients with mood disorders: follow-up over 34-38 years. J Affect Disord 2002; 68: 167-81.

46 Osby U, Brandt L, Correia N, Ekbom A, Sparen P. Excess mortality in bipolar and unipolar disorder in Sweden. Arch Gen Psychiatry 2001; 58: 844-50.

47 Sharma R, Markar HR. Mortality in affective disorder. J Affect Disord 1994; 31: 91-6.

48 Tsuang MT, Woolson RF. Excess mortality in schizophrenia and affective disorders. Do suicides and accidental deaths solely account for this excess? Arch Gen Psychiatry 1978; 35: 1181-5.

49 Tsuang MT, Woolson RF. Mortality in patients with schizophrenia, mania, depression and surgical conditions. A comparison with general population mortality. Br J Psychiatry 1977; 130: 162-6.

50 Teferra S, Shibre T, Fekadu A, Medhin G, Wakwoya A, Alem A, et al. Five-year mortality in a cohort of people with schizophrenia in Ethiopia. $B M C$ Psychiatry 2011; 11: 165

51 Brown S. Excess mortality of schizophrenia. A meta-analysis. Br J Psychiatry 1997: 171: 502-8.

52 Caidwell CB, A Gottesman II. Schizophrenics kill themselves too: a review of risk factors for suicide. Schizophr Bull 1990; 16: 57l-88.

53 Brown S, Kim M, Mitchell C, Inskip H. Twenty-five year mortality of a community cohort with schizophrenia. Br J Psychiatry 2010; 196: 116-21.

54 Bekri AA. Trends in suicide, parasuicide and accidental poisoning in Addis-Ababa, Ethiopia. Ethiop J Health Dev 1999; 13: 247-62.

55 Belete H. Assessment of the Cause of Death and Characteristics of Chronic Illnesses in Addis Ababa with Emphasis on HIV/AIDS (a Community Based Study). Thesis, Addis Ababa University, 2006 (http://www.researchgate.net/ profile/Habtamu_Belete/publication/237461085_ASSESSMENT_OF_THE CAUSE OF DEATH AND CHARACTERISTICS OF CHRONIC IUNESSES IN ADDIS_ABABA_WITH_EMPHASIS_ON_HIVAIDS_(A_COMMUNITY_BASED_ STUDY_/links/02e7e529d8f734e339000000.pdf) 